Graciela Maglia, Introducción, Otros caribes: de las Antillas al continente (sudamérica, centroamérica y norteamérica)

I. El Caribe Como nuevo locus de enUnCiación: ENERGÍA CREADORA Y PROCESOS DE CREOLIZACIÓN

Derek Walcott, El Caribe: ¿Cultura o Mimetismo?

Jim Cohen y Jade LindgaARd, Entrevista a Paul Gilroy. Del Atlántico negro

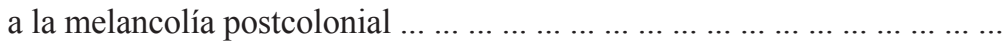
Patrick Chamoiseau, La puesta en relación $\ldots \ldots \ldots \ldots \ldots \ldots \ldots \ldots \ldots \ldots \ldots$ JEAn Bernabé, La elección de la lengua y la creatividad literaria de Aimé

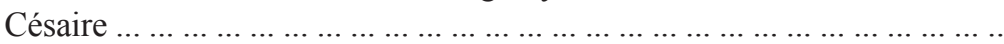

RAPHAËL CONFIANT, Creolidad, diversalidad y mundialización ... ... ........... ERnest PépIn, Por un espacio literario continuo $\ldots \ldots \ldots \ldots \ldots \ldots \ldots \ldots \ldots$ Carlos A. Jáuregui, La otra antropofagia. Oswaldo Costa y la crítica de la

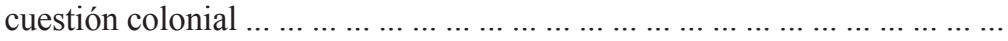

George Lamming, El legado de Eric Williams 301

II. El Caribe centrípeto, el Caribe Centrífugo: LAS DIÁSPORAS

William Luis, Literatura e identidad "afrolatinas" del Caribe en los Estados

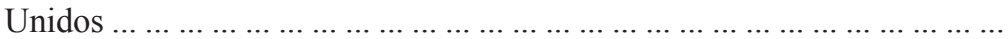

LuZ M. HinCAPIÉ, Rutas del Pacífico: Identidades diaspóricas asiáticas en el Caribe Colombiano 


\section{Orillas continentales del CARiBe}

María Roof, Otros Caribes: Posiciones contestatarias desde la CostaAtlántica

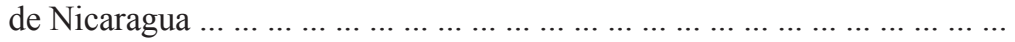

Ligia S. Aldana, 'Paña, palomo y gato...': La leyenda del pañamán en Los pañamanes de Fanny Buitrago, un eslabón del meta-archipiélago caribeño

NAdia Celis, A 50 años de El hostigante verano de los Dioses: Fanny Buitrago

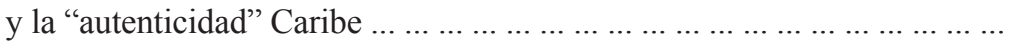

SARAH DE MoJicA, Genealogías de la imagen en las novelas de Ramón Illán Bacca Linares en el marco de la cultura del Caribe Colombiano

\section{ORALIDAD, ORALITURA, LITERATURA}

Graciela Maglia e Yves MoÑIno, Oralitura y oratura palenquera: entre África, Europa y el Caribe

JuAN CRISTÓBAL CASTRO, Mandato y revolución: Cabrera Infante y la pérdida

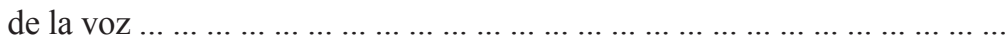

\section{RePosicionAmientos, RESIGNIFICACIONES}

Silvia VALERo, Racialización como espacio político: hacia el "negro consciente" en En la prisión de los sueños, de Eliseo Altunaga ... .........

JANETH CASAS, Representaciones de la sexualidad femenina en la ficción de Chamoiseau y Confiant: La Chabine y Man Chine

\section{NuEVAS VISIBILIDADES, NUEVAS VISUALIDADES}

LuDMILA FERRARI, Un epígrafe cimarrón para la libertad: Monumentalización, silencio y repetición en el archivo de San Basilio de Palenque ... ... . . . . . ...

Áurea María Sotomayor, La alterna Casa de la Laguna: expediente de

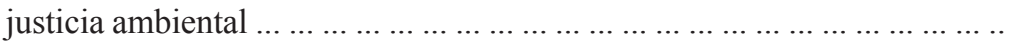




\section{NotA-ReseÑA}

Francisco Aiello, Nuevas perspectivas de los estudios caribeños en la

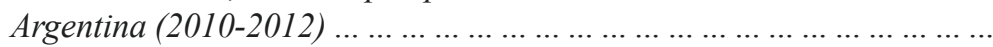

\section{RESEÑAS}

María Eugenia Bancescu sobre Graciela Salto, ed., Ínsulas y poéticas: figuras

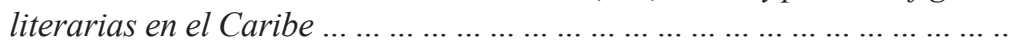
JoHN LIPSKi sobre Graciela Maglia y Armin Schwegler, eds., Palenque (Colombia): oralidad, identidad y resistencia $\ldots \ldots \ldots \ldots \ldots \ldots \ldots \ldots \ldots$ 
